\title{
Use of a Novel Computerized Drill for Pedicle Screw Insertion in the Thoracic and Lumbar Spine: A Cadaveric Study
}

\author{
NICHOLAS SHEPARD, MD, HIEN PHAM, MD, VIVEK NATARAJAN, MD, THOMAS ERRICO, MD, \\ MARK RIEGER, MD \\ Department of Orthopedic Surgery, NYU Langone Orthopedic Hospital, NYU Langone Health, New York, New York
}

\begin{abstract}
Background: A variety of techniques have been utilized to improve the accuracy of pedicle screw instrumentation. Recently, a novel handheld computerized drill system, IntelliSense Drill Technology, has been used in orthopedic trauma to improve drilling accuracy and reduce radiation and iatrogenic injury. The specialized drill technology detects changes in cortical density to prevent inadvertent cortical violation. The aim of this study is to assess the ability of this system to identify pedicle trajectories in the thoracic and lumbar spine compared to a standard freehand technique.

Methods: Two spine surgeons, including 1 senior-level and 1 junior-level attending drilled pedicle screw tracts using a freehand technique and computerized drill technology in 4 cadaveric spines from T2 to S1. A total of 134 pedicle screws were placed, including 70 by the senior surgeon and 64 by the junior surgeon. Cortical violations were assessed using computed tomography after instrumenting each pedicle tract, and procedure time for insertion of pedicle screws was recorded.

Results: A total of $15(22.4 \%)$ and $12(18.2 \%)$ pedicle violations were noted using the freehand and computerized drill technique, respectively $(P=.767)$. Perforations using the computerized drill decreased from $31.1 \%$ in the first attempt to $5.9 \%$ in the second attempt $(P=.027)$. Mean drill time per pedicle using the freehand and computerized drill techniques were comparable $(12.2 \pm 8.4$ versus $12.1 \pm 13.2, P=.871)$, and both surgeons had an improvement in procedure time using the computerized drill (surgeon 1: $12.3 \pm 13.7-5.7 \pm 3.8[\mathrm{SD}], P=.059$; surgeon 2: $20.3 \pm 20.0-$ $10.4 \pm 5.6[\mathrm{SD}], P=.063)$.

Conclusions: We demonstrate the use of a novel drill technology for placement of pedicle screws in the thoracic and lumbar spine. After an initial learning curve, this technology is comparable to use of a freehand technique by both a senior-level and a junior-level attending surgeon in a cadaveric model. Further investigation is needed to identify the clinical role of this technology in spine surgery.
\end{abstract}

New Technology

Keywords: pedicle screw, robotics, spine surgery, thoracolumbar, trajectory

\section{INTRODUCTION}

Roy-Camille is credited with popularizing pedicle screw fixation in North America with his presentation at the American Academy of Orthopaedic Surgeons in 1979 and his subsequent reports regarding the use of pedicle screw stabilization in the lumbar and thoracic spine. ${ }^{1,2}$ This technique has since evolved, with pedicle screws being successfully used in cases of deformity correction, fractures, arthrodesis, and neoplasms. ${ }^{3-7}$ Specifically, the use of pedicle screws in scoliosis has now become the accepted standard replacing previously described techniques for instrumented fusion, including the Harrington rod system, sublaminar hooks and wires, and hybrid instrumentation. This is due in part to improved curve correction with the use of pedicle screw constructs. ${ }^{8,9}$ Proponents of this technique also cite the possibility of 3-column fixation with minimal risk to adjacent structures and the ability to achieve better coronal balance and derotation. $^{10}$

However, this technique is not without complications. The most commonly reported complication is screw malposition, with reported rates ranging widely in the literature from $1.2 \%$ to $65 \% .^{10-16}$ Major complications can also occur, including pulmonary, vascular, and catastrophic neurologic injury. ${ }^{13,17-20}$ Various techniques have been described to minimize these complications and prevent 
aberrant pedicle screw placement. These include modified freehand techniques, computer-assisted navigation, and fluoroscopic guidance.

Potential drawbacks of these newer systems include the need for preoperative computed tomographic (CT) imaging, additional cost, and higher doses of radiation to the surgeon and patient. ${ }^{21}$ Additional technologies that are less reliant on fluoroscopy and do not require additional preoperative imaging include modified drill templates and computerized drill technology. One example is a novel handheld computerized drill system that utilizes integrated software to detect cortical density, thereby helping to improve drill accuracy. The IntelliSense Drill Technology (McGinley Orthopedics, Casper, Wyoming) consists of 2 functional modes: (1) freehand and (2) bicortical mode. In freehand mode, the drill functions similar to that of a standard handheld drill but detects when cortical perforation occurs and reports on the depth of the bone tunnel created. In bicortical mode, the drill software stops the drill's motor when it detects an impending cortical breach, thereby preventing perforation or plunging. Although its application in spine surgery has never been described, the computerized drill may be effective in optimizing accurate pedicle screw placement. The aim of this study is to assess the ability of this technology to identify and create accurate pedicle trajectories in the thoracic and lumbar spine in comparison to a standard freehand technique.

\section{MATERIALS AND METHODS}

\section{Surgical Technique}

A total of 4 cadaver specimens of the whole spine were included in this study ( 2 males and 2 females, age range 71-93 years). Each specimen underwent computerized drilling on one side and freehand technique on the other, with the specimen randomized to determine laterality for each drilling method. Specimens were prepared from $\mathrm{T} 2$ to $\mathrm{S} 1$. One senior-level spine surgeon (surgeon 1) and 1 junior-level surgeon (surgeon 2) were included. Both surgeons received a brief tutorial on the IntelliSense drill prior to using it in this study, but neither surgeon had previous experience with use of the drill in a clinical or research setting.

In the freehand cohort, facetectomies and removal of the inferior 3-5 $\mathrm{mm}$ of the inferior facet were performed to expose the pedicle screw starting point. Freehand technique as described by Kim et $\mathrm{al}^{15}$ was used. A high-speed burr was used to create the pedicle tracts. No fluoroscopic or computerized navigation was used. A flexible ball-tipped palpating device was used to palpate the floor and pedicle walls in standard fashion. After the pedicle tracts had been established, pedicle screws of appropriate length and diameter were inserted.

On the contralateral side, a small portion of the superior articular process was removed to allow for starting point placement of the computerized drill bit, but the facets were otherwise left intact. This allowed the computerized drill with a $2.5-\mathrm{mm}$ drill bit to be used in bicortical mode. When using this mode, the drill motor has an automated stop as the software senses an impending breach of the second cortex based on its assessment of remaining cortical density.

\section{Assessment of Pedicle Screw Tract Accuracy}

Pedicle screw tract accuracy of each method was assessed using fine-cut 3.0-mm CT analysis after the tracts had been drilled and prior to the insertion of pedicle screws. After the pedicle screws were placed, the CT was repeated to assess for cortical breeches, including anterior, medial, and lateral wall violations. The CT images underwent radiologic assessment by a musculoskeletal trained radiologist who was blinded to the technique used to create the pedicle screw tracts.

\section{Learning Curve Assessment}

After cadaver preparation, pedicle tract drilling and screw insertion was video recorded. Two independent observers analyzed the data to determine the time required for pedicle drilling and screw insertion at each level using the computerized drill system and freehand technique for all 4 specimens.

\section{Statistical Methods}

Differences in accuracy of pedicle screw placement between the 2 techniques was measured using the chi-square test. The paired Student $t$ test was used to assess the learning curve and compare time for instrumentation using each technique. All statistical calculations were done via SPSS version 24. (IBM, Armonk, New York). Statistical significance was defined as $P<.05$. 
Table 1. Comparison of pedicle violations between drill techniques on computed tomographic imaging

\begin{tabular}{|c|c|c|c|}
\hline & Freehand Technique, No. (\%) & Computerized Drill Technique, No. (\%) & \\
\hline & $\mathbf{n}=\mathbf{6 7}$ & $n=66$ & $P$ Value \\
\hline \multicolumn{4}{|l|}{ Overall } \\
\hline Before screw placement (total) & $13(19.4)$ & $13(19.7)$ & .553 \\
\hline Lateral wall & $12(17.9)$ & $10(15.2)$ & \\
\hline Medial wall & $1(1.5)$ & $3(4.5)$ & \\
\hline After screw placement (total) & $15(22.4)$ & $12(18.2)$ & .767 \\
\hline Lateral wall & $13(19.4)$ & $11(16.7)$ & \\
\hline \multirow[t]{2}{*}{ Medial wall } & $2(3.0)$ & $1(1.5)$ & \\
\hline & $\mathbf{n}=\mathbf{3 5}$ & $\mathbf{n}=\mathbf{3 5}$ & \\
\hline \multicolumn{4}{|l|}{ Surgeon 1} \\
\hline Before screw placement (total) & $7(20.0)$ & $9(25.7)$ & .569 \\
\hline Lateral wall & $7(20.0)$ & 9 (25.7) & \\
\hline Medial wall & 0 & 0 & \\
\hline After screw placement (total) & $7(20.0)$ & $10(28.6)$ & .492 \\
\hline Lateral wall & $7(20.0)$ & $9(25.7)$ & \\
\hline \multirow[t]{2}{*}{ Medial wall } & 0 & $1(2.9)$ & \\
\hline & $\mathrm{n}=32$ & $\mathrm{n}=31^{\mathrm{a}}$ & \\
\hline \multicolumn{4}{|l|}{ Surgeon 2} \\
\hline Before screw placement (total) & $6(28.7)$ & $4(12.9)$ & .160 \\
\hline Lateral wall & $5(15.6)$ & $1(3.2)$ & \\
\hline Medial wall & $1(3.1)$ & $3(9.7)$ & \\
\hline After screw placement (total) & $8(25.0)$ & $2(6.5)$ & .108 \\
\hline Lateral wall & $6(18.8)$ & $2(6.5)$ & \\
\hline Medial wall & $2(6.3)$ & 0 & \\
\hline
\end{tabular}

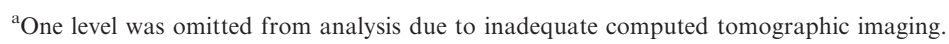

\section{RESULTS}

\section{Comparison of Accuracy}

A total of 134 pedicle screws were placed, including 70 by surgeon 1 (35 freehand and 35 computerized drill) and 64 by surgeon 2 (32 freehand and 32 computerized drill). One screw placed by surgeon 2 using the computerized drill was excluded from analysis due to inadequate CT imaging. Overall, there were no significant differences in incidence of pedicle screw perforation between the freehand and computerized drill techniques on CT analysis before (19.4\% versus $19.7 \%$, $P=.553)$ and after screw placement $(22.4 \%$ versus $18.2 \%, P=.767$ ) (Table 1 and Figure 1). Surgeon 1 had 7 lateral and no medial screw perforations using a freehand technique and 9 lateral and 2 medial breaches with the computerized drill $(P=.492)$ (Figure 2). Surgeon 2 had 6 lateral and 2 medial breaches using a freehand technique and 2 lateral and no medial breaches with the computerized drill $(P=.108)$ (Figure 3). For both surgeons, the majority of pedicle screw perforations occurred in the upper thoracic spine from T2 to T6 regardless of technique.

\section{Learning Curve Assessment}

After optimizing the computerized drill technique, overall lateral and medial perforations using the computerized drill decreased from $28.1 \%$ and $3 \%$ in the first cadaver to $5.9 \%$ and $0 \%$ in the second cadaver $(P=.027)$. Mean drill time per pedicle using the freehand and computerized drill techniques were comparable, with $6.4 \pm 2.3$ and $8.9 \pm 10.3$ seconds, respectively, for surgeon 1 $(P=.175)$ and $18.6 \pm 7.9$ and $15.4 \pm 15.1$ seconds for surgeon $2(P=.284)$. Both surgeons experienced an improvement in procedure time from the first to second cadaver when using the computerized drill technique (surgeon 1: $12.3 \pm 13.7-5.7 \pm 3.8 \mathrm{sec}-$ onds, $P=.059$; surgeon $2: 20.3 \pm 20.0-10.4 \pm 5.6$ seconds, $P=.063$ ).

\section{DISCUSSION}

With increasing use of pedicle screw constructs for a variety of spinal pathology, efforts have been focused on improving accuracy and reducing complications associated with aberrant screw placement. This is the first study assessing the use of a novel computerized handheld drill for pedicle screw placement in the thoracic and lumbar spine. Our 
A

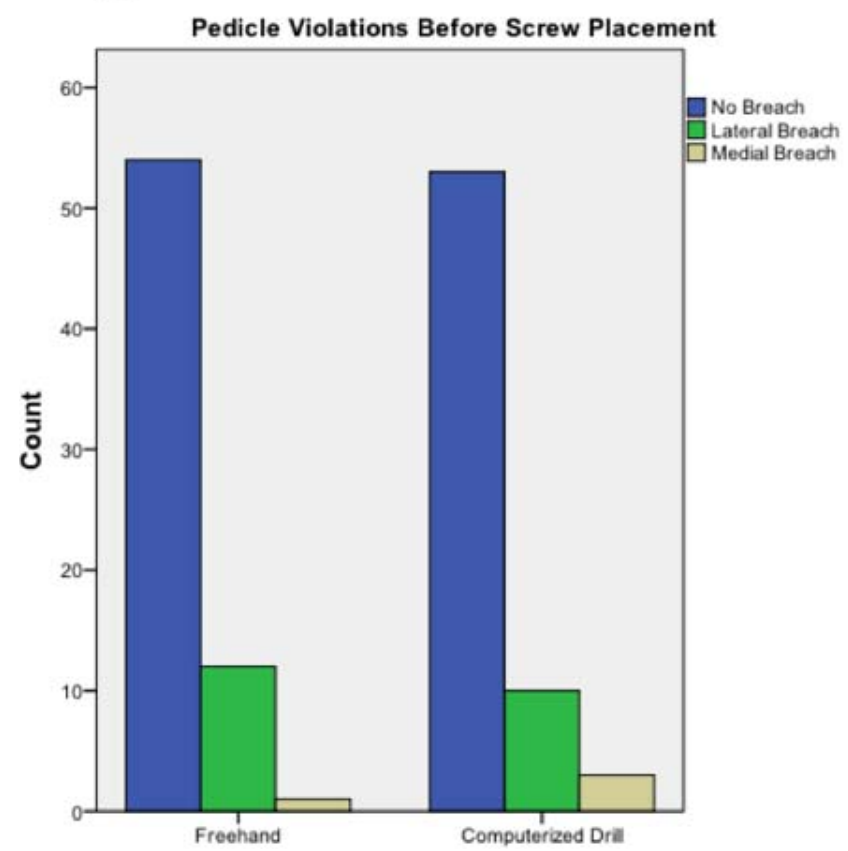

B

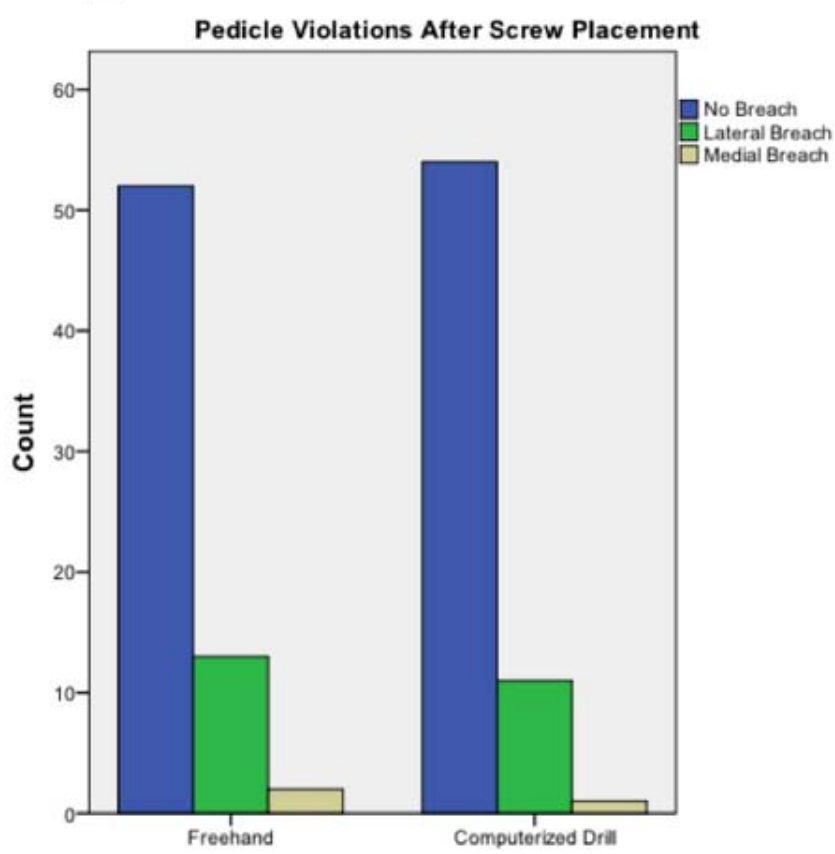

Figure 1. Pedicle violations using freehand and computerized drill techniques (A) before and (B) after screw placement.

overall screw malposition rates of $22.4 \%$ and $18.2 \%$ with a freehand and motorized drill technique, respectively, is comparable with other rates reported in the literature. While there is significant variability, a systematic review by Hicks et al ${ }^{13}$ noted screw malposition in 518 of 4570 screws (4.2\%) on plain films placed in the thoracic spine for pediatric deformity. These lower rates are influenced by the method of assessment of screw perforation. When CT was used postoperatively to assess screw position, rates were significantly higher occurring at $15.7 \%$ per screw inserted. This is similar to those
A

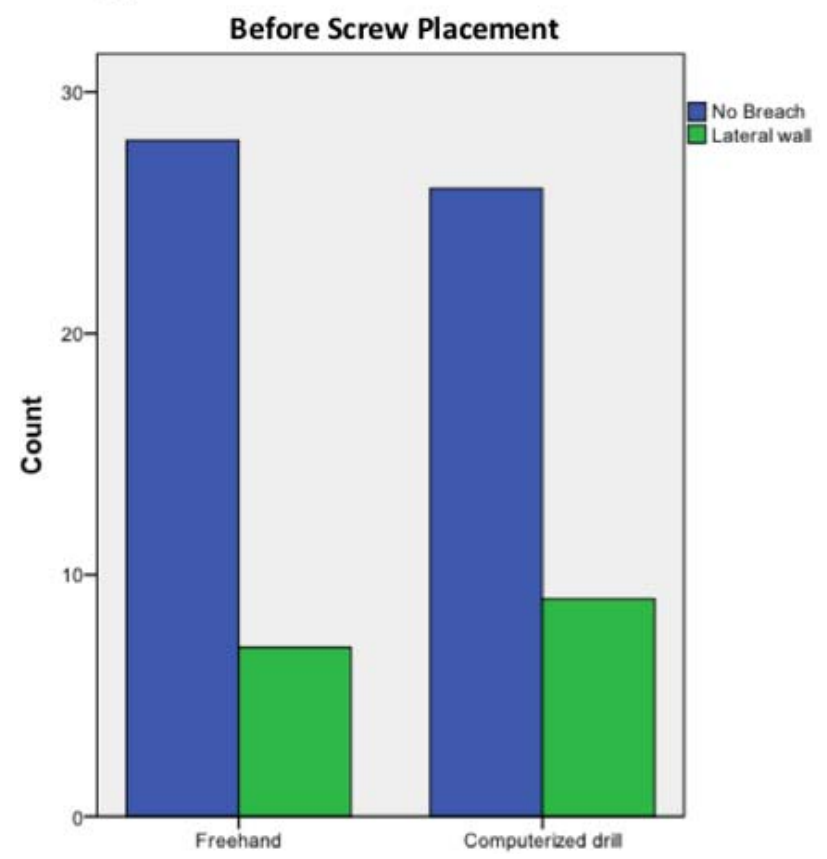

B

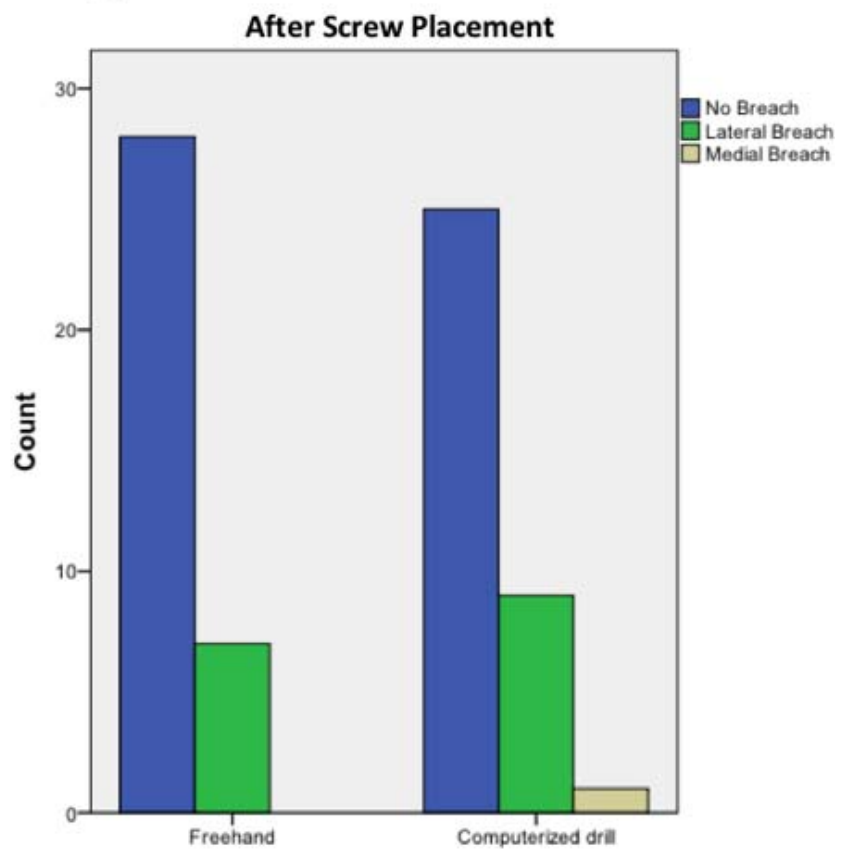

Figure 2. Accuracy of senior surgeon using the freehand and computerized drill techniques (A) before and (B) after screw placement. 
A

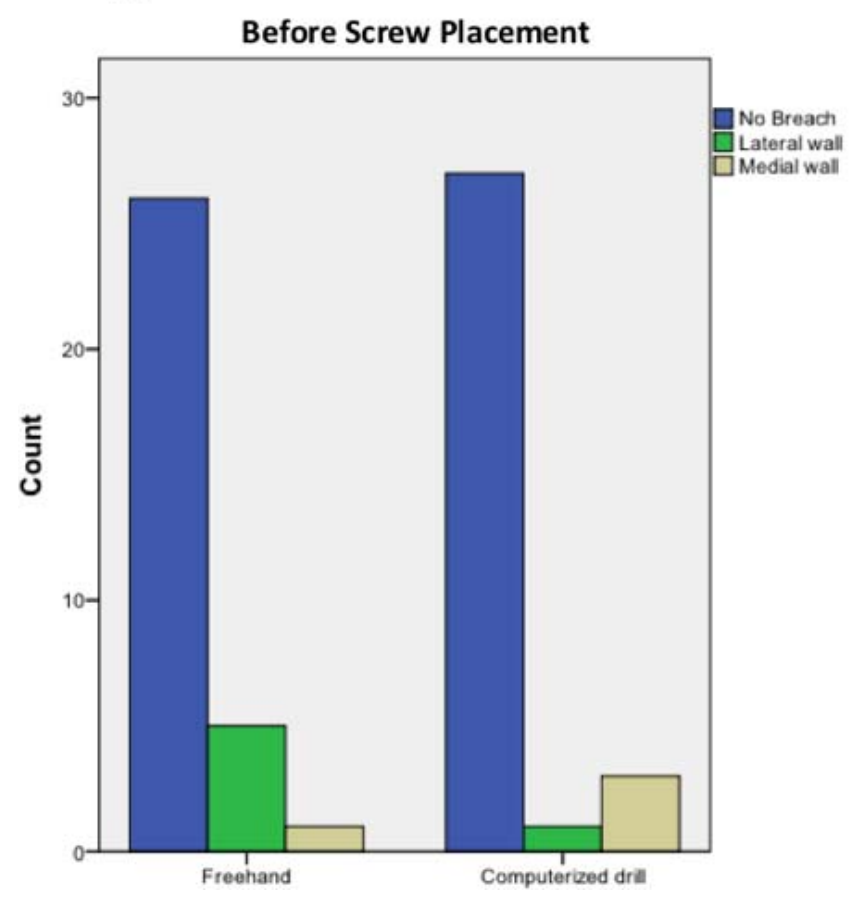

B

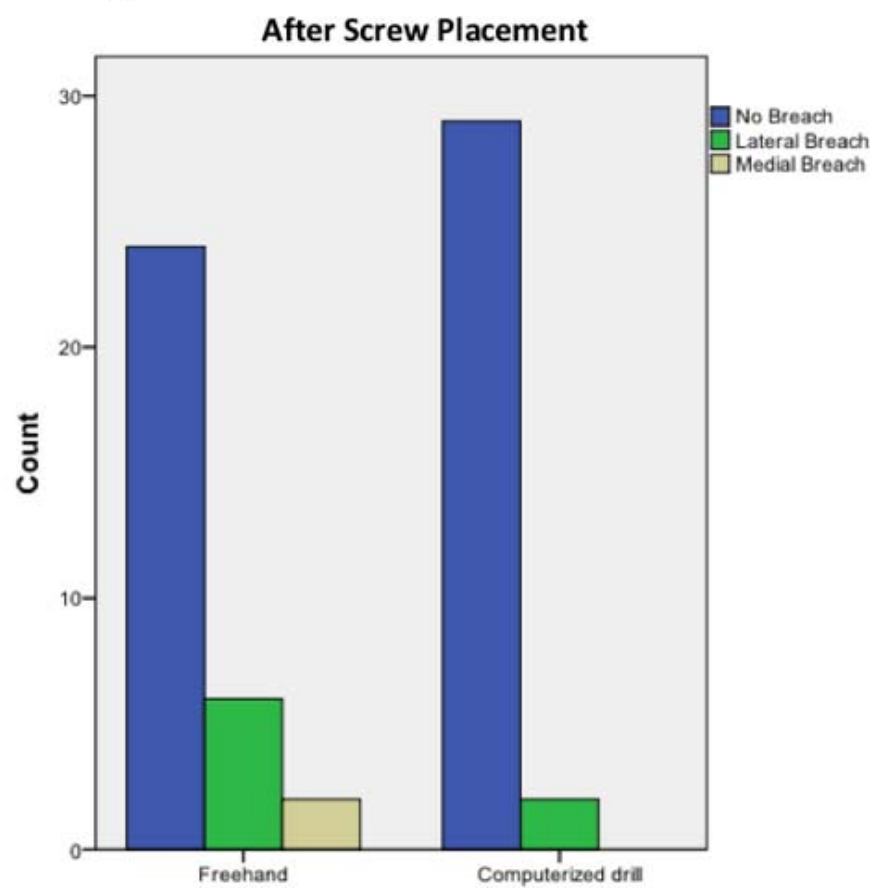

Figure 3. Accuracy of junior surgeon using the freehand and computerized drill techniques (A) before and (B) after screw placement.

findings by Kwan et al, ${ }^{14}$ who noted a $20.3 \%$ perforation rate in 2020 pedicle screws used in adolescent idiopathic scoliosis (AIS) with a $0.1 \%$ rate of symptomatic screw perforation.

While there were a total of 12 perforations after screw placement using the computerized drill, only 1 $(1.5 \%)$ medial perforation occurred. This may be due in part to overcompensation laterally in an effort to avoid medial perforation into the dural sheath. This is consistent with other series that note higher rates of lateral perforation compared to medial breach. ${ }^{22-24}$ Clinically, neurologic deficits as the result of screw malposition are exceedingly rare but occur more commonly with medial perforation. ${ }^{15,25,26}$ Dede et $\mathrm{al}^{25}$ reported on their complications in 591 patients with AIS. They noted a $0.6 \%$ reoperation rate and $0.14 \%$ rate of symptomatic misplaced pedicle screws, all of which were medial.

Once the computerized drill technique had been optimized, including removal of a portion of the superior articular process, significant improvements in the perforation rates between the first and second specimens were noted for both surgeons. This included a significant reduction in overall perforation rates from $31.3 \%$ to $5.9 \% \quad(P=.027)$. In addition, both had an approximately $50 \%$ decrease in time per pedicle screw in the second specimen using the computerized drill. The short learning curve associated with this device may be due to increased familiarity with the tactile feedback offered by the computerized drill as well as a better understanding of the unique surgical technique. These findings were suggestive of a short learning curve for both a senior-level and a junior-level attending surgeon, after which time accuracy and speed were similar to that of a standard freehand technique. This is in contrast to longer learning curves that have been associated with other methods of pedicle screw placement. ${ }^{27,28}$

There were several limitations to this study. First, there was limited sample size consisting of 4 cadavers with 134 pedicle screws. If a larger sample was used, discrepancies in accuracy between the 2 techniques may have become more apparent, or the learning curve for the IntelliSense drill may have become more pronounced. Second, all cadavers used in this study were free of deformity, and therefore the use of this technique in AIS or other technically challenging cases warrants further examination.

\section{CONCLUSIONS}

After a brief initial learning curve, use of a novel automated computerized drill technology for place- 
ment of pedicle screws in the thoracic and lumbar spine is comparable to a freehand technique by both a senior-level and a junior-level attending surgeon in a cadaveric model. Further investigation is needed to identify the clinical role of this technology in spine surgery.

\section{REFERENCES}

1. Roy-Camille R, Saillant G, Mazel C. Internal fixation of the lumbar spine with pedicle screw plating. Clin Orthop Relat Res. 1986;(203):7-17.

2. Roy-Camille R, Saillant G, Mazel C. Plating of thoracic, thoracolumbar, and lumbar injuries with pedicle screw plates. Orthop Clin North Am. 1986;17(1):147-159.

3. Dobbs MB, Lenke LG, Kim YJ, Kamath G, Peelle MW, Bridwell KH. Selective posterior thoracic fusions for adolescent idiopathic scoliosis: comparison of hooks versus pedicle screws. Spine (Phila Pa 1976). 2006;31(20):2400-2404.

4. Yue JJ, Sossan A, Selgrath C, et al. The treatment of unstable thoracic spine fractures with transpedicular screw instrumentation: a 3-year consecutive series. Spine (Phila Pa 1976). 2002;27(24):2782-2787.

5. Gertzbein SD, Betz R, Clements D, et al. Semirigid instrumentation in the management of lumbar spinal conditions combined with circumferential fusion. A multicenter study. Spine (Phila Pa 1976). 1996;21(16):1918-1925; discussion 2526.

6. Benzel EC, Baldwin NG. Crossed-screw fixation of the unstable thoracic and lumbar spine. $J$ Neurosurg. 1995;82(1):11-16.

7. Jonsson B, Sjostrom L, Olerud C, Andreasson I, Bring J, Rauschning W. Outcome after limited posterior surgery for thoracic and lumbar spine metastases. Eur Spine J. 1996;5(1):36-44.

8. Halm H, Niemeyer T, Link T, Liljenqvist U. Segmental pedicle screw instrumentation in idiopathic thoracolumbar and lumbar scoliosis. Eur Spine J. 2000;9(3):191-197.

9. Hamill CL, Lenke LG, Bridwell KH, Chapman MP, Blanke K, Baldus C. The use of pedicle screw fixation to improve correction in the lumbar spine of patients with idiopathic scoliosis. Is it warranted? Spine (Phila Pa 1976). 1996;21(10):1241-1249.

10. Gaines RW Jr. The use of pedicle-screw internal fixation for the operative treatment of spinal disorders. $J$ Bone Joint Surg Am. 2000;82-A(10):1458-1476.

11. Liljenqvist UR, Halm HF, Link TM. Pedicle screw instrumentation of the thoracic spine in idiopathic scoliosis. Spine (Phila Pa 1976). 1997;22(19):2239-2245.

12. Kuklo TR, Lenke LG, O'Brien MF, Lehman RA Jr, Polly DW Jr, Schroeder TM. Accuracy and efficacy of thoracic pedicle screws in curves more than 90 degrees. Spine (Phila Pa 1976). 2005;30(2):222-226.

13. Hicks JM, Singla A, Shen FH, Arlet V. Complications of pedicle screw fixation in scoliosis surgery: a systematic review. Spine (Phila Pa 1976). 2010;35(11):E465-E470.

14. Kwan MK, Chiu CK, Gani SM, Wei CC. Accuracy and safety of pedicle screw placement in adolescent idiopathic scoliosis patients: a review of 2020 screws using computed tomography assessment. Spine (Phila Pa 1976). 2017;42(5):326-335.

15. Kim YJ, Lenke LG, Bridwell KH, Cho YS, Riew KD. Free hand pedicle screw placement in the thoracic spine: is it safe? Spine (Phila Pa 1976). 2004;29(3):333-342; discussion 42.

16. Kim YJ, Lenke LG, Cheh G, Riew KD. Evaluation of pedicle screw placement in the deformed spine using intraoperative plain radiographs: a comparison with computerized tomography. Spine (Phila Pa 1976). 2005;30(18):2084-2088.

17. Ogura Y, Watanabe K, Hosogane N, Toyama Y, Matsumoto M. Acute respiratory failure due to hemothorax after posterior correction surgery for adolescent idiopathic scoliosis: a case report. BMC Musculoskelet Disord. 2013; 14:132.

18. Choi JB, Han JO, Jeong JW. False aneurysm of the thoracic aorta associated with an aorto-chest wall fistula after spinal instrumentation. J Trauma. 2001;50(1):140-143.

19. Minor ME, Morrissey NJ, Peress R, et al. Endovascular treatment of an iatrogenic thoracic aortic injury after spinal instrumentation: case report. J Vasc Surg. 2004;39(4):893-896.

20. Wegener B, Birkenmaier C, Fottner A, Jansson V, Durr HR. Delayed perforation of the aorta by a thoracic pedicle screw. Eur Spine J. 2008;17(suppl 2):S351-S354.

21. Villard J, Ryang YM, Demetriades AK, et al. Radiation exposure to the surgeon and the patient during posterior lumbar spinal instrumentation: a prospective randomized comparison of navigated versus non-navigated freehand techniques. Spine (Phila Pa 1976). 2014;39(13):1004-1009.

22. Belmont PJ Jr, Klemme WR, Dhawan A, Polly DW Jr. In vivo accuracy of thoracic pedicle screws. Spine (Phila Pa 1976). 2001;26(21):2340-2346.

23. Grauer JN, Vaccaro AR, Brusovanik G, et al. Evaluation of a novel pedicle probe for the placement of thoracic and lumbosacral pedicle screws. J Spinal Disord Tech. 2004;17(6):492-497.

24. Chan CYW, Kwan MK. Zonal differences in risk and pattern of pedicle screw perforations in adolescent idiopathic scoliosis (AIS): a computerized tomography (CT) review of 1986 screws. Eur Spine J. 2018;27(2):340-349.

25. Dede O, Ward WT, Bosch P, Bowles AJ, Roach JW. Using the freehand pedicle screw placement technique in adolescent idiopathic scoliosis surgery: what is the incidence of neurological symptoms secondary to misplaced screws? Spine (Phila Pa 1976). 2014;39(4):286-290.

26. Suk SI, Kim WJ, Lee SM, Kim JH, Chung ER. Thoracic pedicle screw fixation in spinal deformities: are they really safe? Spine (Phila Pa 1976). 2001;26(18):2049-2057.

27. Gang C, Haibo L, Fancai L, Weishan C, Qixin C. Learning curve of thoracic pedicle screw placement using the free-hand technique in scoliosis: how many screws needed for an apprentice? Eur Spine J. 2012;21(6):1151-1156.

28. Samdani AF, Ranade A, Sciubba DM, et al. Accuracy of free-hand placement of thoracic pedicle screws in adolescent idiopathic scoliosis: how much of a difference does surgeon experience make? Eur Spine J. 2010;19(1):91-95.

Disclosures and COI: TE (personal fees from Fastenetix and $\mathrm{K} 2 \mathrm{M}$; other from International Spine Study Group Foundation [ISSG], Medtronic, Paradigm Spine, and Pfizer, outside the submitted 
work). MR (other from McGinley Orthopedics and GammaCore, outside the submitted work). For the remaining authors none declared. Funding for the cadavers was provided by a grant from K2M. The funding body played no role in the study design, collection analysis, interpretation of data, or manuscript writing.

Corresponding Author: Nicholas Shepard, MD, 301 East 17th St., 14th Floor, New York, NY
10003. Phone: (315) 256-4739; Email: Nicholas. shepard@nyumc.org.

Published 31 August 2019

This manuscript is generously published free of charge by ISASS, the International Society for the Advancement of Spine Surgery. Copyright (c) 2019 ISASS. To see more or order reprints or permissions, see http://ijssurgery.com. 